\title{
Changes in MIDAS, Perceived Stress, Frontalis Muscle Activity and Non-Steroidal Anti-Inflammatory Drugs Usage in Patients with Migraine Headache without Aura following Ayurveda and Yoga Compared to Controls: An Open Labeled Non-Randomized Study
}

\author{
M.S. Vasudha N.K. Manjunath H.R. Nagendra \\ Division of Yoga and Life Sciences, Swami Vivekananda Yoga Anusandhana Samsthana (S-VYASA) \\ A Deemed to be University, Bengaluru, India
}

\section{Keywords}

Integrative medicine - Ayurveda - Yoga therapy .

Migraine $\cdot$ Pain $\cdot$ Disability $\cdot$ Stress

\begin{abstract}
Background: There has been a significant increase in the use of complementary and integrative medicine to provide longterm healing solutions in migraine headache patients. Knowing the limitations of conventional medical approach, the present study evaluated the influence of two Indian traditional systems of medicine on migraine-related disability, autonomic variables, perceived stress, and muscle activity in patients with migraine headache without aura. Methods: Thirty subjects recruited to the Ayurveda and Yoga (AY) group underwent traditional Panchakarma (Bio-purification) using therapeutic Purgation followed by yoga therapy, while 30 subjects of control (CT) group continued on symptomatic treatment (non-steroidal anti-inflammatory drugs [NSAID's]) for 90 days. Migraine disability assessment score, perceived stress, heart rate variability (HRV), and surface electromyog-
\end{abstract}

raphy (EMG) of frontalis muscle were measured on day 1, day 30, and day 90 in both groups. Results: Significant reduction in migraine disability and perceived stress scores were observed in the AY group. The low-frequency component of the HRV decreased significantly, the high-frequency component increased and their ratio showed improved sympathovagal balance. The EMG showed decreased activity of the frontalis muscle in the AY group compared to the control group. Conclusion: The integrative approach combining Ayurveda and Yoga therapy reduces migraine-related disability, perceived stress, sympathetic arousal, and muscle tension.

(c) 2018 S. Karger AG, Basel

\section{Introduction}

Migraine headache is a neurological disorder, prevalent across the world and is associated with varied degrees of disability, thereby affecting the work capacity and productivity of an individual. It is associated with comorbidities and modifiable risk factors [1].

\section{KARGER}

(c) 2018 S. Karger AG, Basel

E-Mail karger@karger.com

www.karger.com/aon
Dr. Vasudha M. Sharma

Division of Yoga and Life Sciences, S-VYASA University

Prashanthi Kutiram, Jigani (Hobli), Anekal (Taluk)

Bengaluru, Karnataka 560106 (India)

E-Mail vasudhamsharma @ gmail.com 
Functional disability associated with migraine can lead to physical, mental, and social consequences [2], and it is commonly measured through the migraine disability assessment questionnaire (MIDAS) [3]. An episode of migraine is triggered by several factors including stress which is either physical or mental in nature [4]. The subjective perception of the impact of stress is measured through perceived stress scale, and studies show a higher incidence of perceived stress in migraineurs [5].

Stress can induce changes in the autonomic nervous system, which is measured non-invasively through heart rate variability (HRV). Migraine headache is known to induce autonomic imbalance. The sympathetic activity is heightened not only during the attacks but also during headache-free states [6].

Studies on headache patients also show an increased muscle activity compared to healthy controls [7], and cognitive stress is a known precursor for the same [8].

Conventional medicines used in migraine have always been derived from other class of drugs and showed limitations in providing satisfactory relief without side effects [9]. The treatment approach, therefore, has to be more than a prescription. Hence, an integrative approach to the management of migraine is essential.

Ayurveda and Yoga therapy are two ancient Indian systems of medicine which are used effectively in health and disease. Their integration offers a holistic approach, which would promote mind-body medicine in a comprehensive manner. Furthermore, Ayurveda therapies are known to influence physiological processes including autonomic modulation [10] and metabolic profiles [11]. In case of migraine headache, it was reported earlier that an Ayurveda-based polyherbal formulation administered for 90 days showed a significant decrease in migrainerelated disability, frequency, and intensity [12]. However, no studies are available till date that demonstrate the underlying physiological mechanisms.

Also, there are more number of studies on Yoga compared to Ayurveda in stress and pain management. The beneficial effects of Yoga have been attributed to autonomic balance shifting towards vagal dominance, reduced biochemical markers of stress such as cortisol, reduced anxiety, and improved psychological well-being [13]. The evidence further shows that biofeedback and progressive muscular relaxation were also effective in reducing frontalis EMG activity in migraine headache patients [14].

Keeping in view the limitations of conventional treatment and the possible beneficial effects of Ayurveda and Yoga therapies, the present study aimed at evaluating the role of an integrated traditional Indian medicine-based intervention in the management of migraine headache. The objective was to comprehensively understand its influence on autonomic variables, surface electromyogram (sEMG), perceived stress, and migraine-related disability.

\section{Methods}

The subjects were recruited from Samatvam Holistic Health Center, Bengaluru, Karnataka in South India. The study protocol was approved by the Institutional Ethics Committee (RES/IECSVYASA/23/2013), and the study was conducted between 2015 and 2017. The study is registered with the Clinical Trials Registry of India (CTRI/2017/10/010074). A total of 86 individuals who were clinically diagnosed with migraine headache were screened based on inclusion and exclusion criteria, and 60 subjects were selected for the study. The recruitment was based on self-selection by the subjects to either Ayurveda and Yoga (AY) or Control (CT) groups. Subjects were explained about the study protocol, and a signed informed consent was obtained before recruitment. They were also given the choice to withdraw from the study at any stage. The sample size was calculated using the G Power software from a previous study [12], with an effect size of $1.31, \alpha=0.05$ and power $=0.95$. The required sample size was 19 subjects in each group. Considering the compliance-related issues, and to improve the statistical impact, a sample size of 30 subjects in each group was considered.

Inclusion criteria: Subjects belonging to both genders, between 18 and 46 years of age with a headache history for more than 1 year, 5 or more attacks of headache in 3 months, willingness to take oral Ayurveda medicine, practicing Yoga, following the dietary restrictions for 75 days, and completing the headache dairy were included.

The diagnostic criteria were based on the International Classification of Headache Disorders (3rd edition) of the International Headache Society, 2013 [15].

Exclusion criteria: Subjects with primary psychiatric disorders (depression, anxiety, psychosis), major medical illness like renal, hepatic, neurological and cardiac diseases, pregnancy, pure menstrual migraine, subjects on Ayurveda or Yoga intervention for the past 6 months and subjects on conventional prophylactic treatment were excluded from the study.

The present study was a prospective matched controlled trial. Subjects were recruited as and when they approached the physician who referred them to an investigator. Subjects willing to undergo Ayurveda and Yoga interventions were allocated to the AY group, while the others who chose to continue with symptomatic treatment were recruited to the CT group. The groups were matched for age and gender. Subjects of the AY group and CT group were assessed on days 1, 30, and 90. The assessments were carried out in headache-free states and in non-menstrual phase in case of female subjects.

\section{Assessments}

Migraine Disability Assessment

MIDAS is a short, self-administered questionnaire used to quantify headache-related disability in a span of 3 months. It has a set of 5 questions, and the total score is based on the number of 
Table 1. The 4-point grading system for MIDAS questionnaire

\begin{tabular}{lll}
\hline Grade & Disability & Score \\
\hline I & Little or no disability & $0-5$ \\
II & Mild & $6-10$ \\
III & Moderate & $11-20$ \\
IV & Severe & $21+$ \\
\hline
\end{tabular}

days marked against each question. The grades and respective scores are mentioned in Table 1 . The reliability and validity of the questionnaire are assessed and well-established [3].

Perceived Stress Scale 10

Perceived stress scale 1 (PSS) measures the perceived level of stress as a function of objective stressful events, coping processes, and personality factors. PSS-10 was selected due to its superior psychometric properties [16]. Each item is rated on a 5-point scale ranging from never (0) to almost always (4). Items 4, 5, 7, and 8 are the positively stated items and they were reverse scored. The sum of all 10 items indicated the levels of perceived stress. Scores between 0 and 13 were considered as low stress, 14-26 as moderate stress, and 27-40 as high perceived stress.

Autonomic Variables and Surface Electromyography

An 8-channel fully integrated data acquisition system (Power lab 15T) from AD instruments, Australia was used for simultaneous recording of Heart Rate, Respiratory Rate, HRV, and surface electromyography (sEMG).

Assessments were done in a dimly lit, sound attenuated room. Subjects were asked to sit on an armless chair with back support by placing their feet on a non-conducting material. During recordings, they were instructed to close their eyes and maintain normal breathing. Heart rate, respiratory rate, and sEMG were recorded simultaneously for a duration of 3 min during frowning (by raising the eyebrows), which produced voluntary muscle contraction.

The electrocardiogram (ECG) was recorded using standard limb lead II configuration by placing clamp ECG electrodes with electrode gel. Data were acquired at a sampling rate of $1,024 \mathrm{~Hz}$. The heart rate variability was derived from ECG by computing the successive RR intervals.

Respiratory rate was recorded through a piezo respiratory belt transducer. This was used to generate a voltage with a change in thoracic circumference due to respiration. The output range was between 20 and $400 \mathrm{mV}$, with a sensitivity of $4.5 \pm 1 \mathrm{mV} / \mathrm{mm}$.

The sEMG of the frontalis muscle was recorded using 2 pregelled silver chloride electrodes placed on the forehead with a distance of $2 \mathrm{~cm}$ between them, and approximately $2.5 \mathrm{~cm}$ above each eyebrow along with a shared ground electrode [17]. The sEMG was recorded with a sampling rate of $1,000 \mathrm{~Hz}$, bandwidth of 20-500 $\mathrm{Hz}$, and a maximum input impedance of $5 \Omega$. A low pass notch filter was applied at $50 \mathrm{~Hz}$.

\section{Data Extraction}

Lab Chart 8 software was used to extract the data offline. Heart rate, HRV, respiratory rate, and EMG were derived separately from the data collected on days 1, 30, and 90.
The noise-free ECG data excluding ectopic beats were selected for further analysis. Heart rate was obtained as beats per minute, averaging it across $3 \mathrm{~min}$. The Lab chart software also processed the ECG signals by identifying successive RR intervals to extract both frequency domain and time domain measures of HRV. The low frequency (LF), high frequency (HF), and LF/HF ratio expressed as normalized units were used as frequency domain measures. While, the SD of RR Intervals, the square root of the mean squared differences of successive $\mathrm{NN}$ intervals, and the proportion derived by dividing NN50 by the total number of NN intervals (pNN50) were derived as time domain measures.

The respiratory rate was derived as the number of breath cycles per minute after averaging it across $3 \mathrm{~min}$ by computing successive inspiratory and expiratory cycles.

The sEMG recording obtained during the 3 min voluntary contraction was used to derive RMS EMG and integral EMG [18].

\section{Interventions}

Ayurveda treatment of Virechana (therapeutic purgation) followed by Yoga therapy was given to the subjects of the AY group. Following the assessments on day 1, Deepana (Digestive) Hinguvachadi churna (polyherbal powder) [20] was given for the first 3 days. From day 4, Abhyantara snehapana (internal oleation) with Kallyanaka Ghrita (a polyherbal preparation made with clarified butter) [19] was administered on empty stomach between 7 and 8 a.m. in increasing dosage ranging from 30 to $150 \mathrm{~mL}$ for 3-5 days until Samyak Snighdha Lakshanas (adequacy of internal oleation) were seen. Following this, Sarvanga Abhyanga (full body oil application) with Shuddha Tila taila (pure Sesame oil) and Swedana (steam bath) was administered for 3 days. The next day (maximum by day 12), Virechana (therapeutic purgation) was induced by administering Trivrit lehyam (polyherbal paste) [19]. The process of Virechana was reported earlier as safe and efficacious with no imbalance in serum electrolyte levels [20]. Samsarjana krama (dietary regimen) for 3-5 days (Day 12-14/16) was specified based on Shuddhi (degrees of cleansing).

Shamana Oushadhi (oral medication for pacification) was started between days 15 and 17 and was continued for a span of 75 days. Pathyakshadhatradi Kashaya (polyherbal decoction) [21], $15 \mathrm{~mL}$, $30 \mathrm{~min}$ before breakfast and dinner with $45 \mathrm{~mL}$ of warm water was advised for oral use. Kachoradi churna (polyherbal powder) [22], topical use as a paste mixed with milk (at room temperature) on the forehead once a day. There was a special mention of Pathya and Apathya (Do's and Don'ts regarding diet and lifestyle). The composition of each polyherbal formulation and the dosage are mentioned in Table 2.

The subjects were allowed to take oral analgesics (Non-steroidal anti-inflammatory drugs, NSAID), as and when required based on the intensity of pain tolerable to them, and the same was noted in their diary for medication use.

Yoga therapy: The specially designed integrated Yoga therapy module for migraine included loosening exercises, breathing exercises, asanas (postures), pranayama (regulated breathing), relaxation techniques, and chanting. Yoga was practiced for $40 \mathrm{~min}$ daily, beginning from day 15 to 17 of the treatment for 7 days as personalized sessions under the supervision of a trained Yoga therapist. The subjects were asked to practice the same module at home, 5 days a week until day 90 . Female subjects were advised not to practice yoga during the first 3 days of menstrual cycle. The yoga therapy module is detailed in Table 3. 
Table 2. List of polyherbal preparations (with their botanical names) used across Ayurveda treatment period and their prescribed quantity in the formulation

a. Hinguvachadi Churna [19]. It is prepared with one part of each of the ingredients mentioned below. They are powdered separately and mixed together. Dosage: $2.5-5 \mathrm{~g}, 30 \mathrm{~min}$ before food with warm water

\begin{tabular}{ll}
\hline Sanskrit name & Botanical name \\
\hline $\begin{array}{l}\text { Shuddha Hingu } \\
\text { (processed with Ghee) }\end{array}$ & Ferula asafetida \\
Vacha & \\
Vijaya & Acorus calamus \\
Pashugandha & Terminalia chebula \\
Dadima & Cleome gynandra \\
Dipyaja(Ajwain) & Punica granatum \\
Dhanya & Trachyspermum ammi \\
Pata & Coriandrum sativum \\
Pushkaramoola & Cyclea peltata \\
Shati & Inula racemosa \\
Hapusha & Hedychium spicatum \\
Agni & Sphaeranthus indicus \\
Yavakshar & Plumbago zeylanica \\
Svarjika kshara & Alkali preparation \\
Saindava lavana & made of Hordeum vulgare \\
Sauvarchala lavana & Sarjika kshara \\
Vida lavana & Rock salt \\
Shunti & Black salt \\
Maricha & Type of black salt \\
Pippali & Zingiber officinalis \\
Ajaji & Piper nigrum \\
Thavya & Piper longum \\
Vetasamla(Amlavetasa) & Cuminum cyminum \\
& Piper chaba \\
& Rhus parviflora \\
Garcinia morella \\
\end{tabular}

b. Kallyanaka Ghrita [19]. 12 g each of the below mentioned ingredients are used to make a medicated ghee (clarified butter)

\begin{tabular}{ll}
\hline Sanskrit name & Botanical name \\
\hline Haritaki & Terminalia chebula \\
Vibhitaki & Terminalia bellirica \\
Amalaki & Emblica officinalis \\
Vishala & Citrulus cholocynthis \\
Bhadra ela & Amomum subulatum \\
Devadaru & Cedrus deodara \\
Elavaluka & Prunus avium \\
Sariva & Hemidesmus indicus \\
Haridra & Turmeric \\
Daruharidra & Berberis aristata \\
Shalaparni & Desmodium gangeticum \\
Prishnaparni & Uraria picta \\
Phalini & Callicarpa macrophylla \\
Nata & Valeriana wallichi \\
Brihati & Solanum indicum \\
\hline
\end{tabular}

\begin{tabular}{ll}
\hline Sanskrit name & Botanical name \\
\hline Kushta & Saussurea lappa \\
Manjishta & Rubia cordifolia \\
Nagakeshara & Mesua ferrea \\
Dadimaphalatwak & Punica granatum \\
Vella & Embelia ribes \\
Talisapatra & Abbies webbiana \\
Ela & Elettaria cardamomum \\
Malati & Jasminum sambac \\
Utpala & Nymphea stellata \\
Danti & Baliospermum montanum \\
Padmaka & Prunus poddum \\
Hima & Sandalwood -Santalum album \\
Sarpi & Ghee - 768 g \\
\hline
\end{tabular}

Manufacturer - Arya Vaidya Pharmacy, Coimbatore, India, a GMP certified company.

c. Trivrit Lehyam [19]. Trivrit - Operculina turpethum. Preparation - $25 \mathrm{~g}$ of the powder is added with $400 \mathrm{~mL}$ of water, boiled and reduced to $100 \mathrm{~mL}$, filtered. To this Trivrit Kashaya, $25 \mathrm{~g}$ of Trivrit powder is again added, along with $50 \mathrm{~g}$ of sugar and mixed well. 25 $\mathrm{mL}$ of honey and $5 \mathrm{~g}$ each of cinnamon, cardamom, and cinnamon fine powder is added to obtain the sweet paste

\begin{tabular}{lll}
\hline Sl. No. & Ingredients & Quantity \\
\hline 1 & Trivrit Kashaya & $100 \mathrm{~mL}$ \\
2 & Trivrit Churna & $25 \mathrm{~g}$ \\
3 & Sugar & $50 \mathrm{~g}$ \\
4 & Honey & $25 \mathrm{~mL}$ \\
5 & Cinnamon & $5 \mathrm{~g}$ \\
6 & Cardamom & $5 \mathrm{~g}$ \\
7 & Cinnamon leaves powder & $5 \mathrm{~g}$ \\
\hline
\end{tabular}

Manufacturer - Arya Vaidya Pharmacy, Coimbatore, India, a GMP certified company.

d. Pathyakshadhatradi Kashaya [21]. Herbal decoction is prepared from $10 \mathrm{~g}$ each of the following herbs

\begin{tabular}{ll}
\hline Sanskrit name & Botanical name \\
\hline Pathya & Terminalia chebula \\
Aksha & Terminalia bellirica \\
Dhatri (Amla) & Emblica officinalis \\
Bhunimba & Andrographis paniculata \\
Nisha (Turmeric) & Curcuma longa \\
Nimba (Neem) & Azadirachta indica \\
Amruta & Tinospora cordifolia \\
\hline
\end{tabular}

Dosage - $15 \mathrm{~mL}$ twice daily before breakfast and dinner mixed with $45 \mathrm{~mL}$ of warm water. Manufacturer - Arya Vaidya Pharmacy, Coimbatore, India, a GMP certified company. 
Table 2. (continued)

e. Kachoradi churna [22]. Equal quantities of herbal powders mentioned below are used to make the powder

\begin{tabular}{ll}
\hline Sanskrit name & Botanical name \\
\hline Kachora & Curcuma zedoaria \\
Dhatri & Emblica officinalis \\
Manjishta & Rubia cordifolia \\
Yashti & Glycyrrhiza glabra \\
Daru & Cedrus deodara \\
Silajitu & Asphaltum \\
Vedhi & Ferula foetida \\
Rohini & Andrographis paniculata \\
Tintrinisira & Tamarindus indicus \\
Kumkuma & Crocus sativus \\
Indu & Camphor \\
Varivaha & Cyperus rotundus \\
Rochanam & Mallotus phillippenensis \\
Bala & Sida cordifolia \\
Laja & Oryza sativa \\
Jala & Coleus zeylanicus \\
Usira & Vetiveria zizanioides \\
Pushkaramoola & Innula racemosa \\
\hline
\end{tabular}

Dosage $-1 / 2$ tsp to be mixed with milk and applied on the forehead. Manufacturer - Arya Vaidya Pharmacy, Coimbatore, India, a GMP certified company.

\section{Control Group}

The subjects who agreed to participate in the trial but preferred to continue on oral analgesics (NSAIDs) for symptomatic relief as per the prescription of a general physician or neurologist were included under this group. They were asked not to practice yoga nor follow Ayurveda during the study period. They were given an option to undergo the same therapy protocol as given for the AY group after the study period.

Subjects of both groups were monitored once in 2 weeks over a telephonic call and visited the investigator once a month. The subjects were free to withdraw from the study at any stage if they felt the conditions were not conducive.

\section{Data Analysis}

The data were analyzed using Statistical Packages for Social Sciences (SPSS), version 23. The normality and homogeneity were assessed using Kolmogorov-Smirnov test. The missing values were replaced by intention-to-treat analysis. The data of individual variables were analyzed using a repeated measures analysis of variance with one within-subjects factor (Time) and one between subjects factor (Groups). Multiple comparisons were made across mean values using a post-hoc analysis with Bonferroni correction. The values were considered significant if $p<0.05$.

\section{Results}

The AY group comprised 30 (8 male and 22 female) subjects, with an average age $\pm \mathrm{SD}$ of $33.83 \pm 6.84$ years. The CT group had an equal number of subjects matched for age and gender, with an average age \pm SD of $31.46 \pm$ 7.81 years. The demographic and clinical characteristics are detailed in Table 4. There was one drop out in the AY group on day 90 and one each from the CT group on days 30 and 90 . The RM analysis of variance with post-hoc analysis (with Bonferroni correction) showed significant differences within and between subjects.

MIDAS: There was a significant difference in both within-subjects factor (Time, $p<0.001$ ) as well as between subjects factor (Groups, $p<0.05$ ). Also, the interaction between Time and Groups was significant $(p<$ 0.001 ). The post-hoc analysis with Bonferroni correction suggested that there was a significant reduction in MIDAS scores for the AY group on days 30 and 90 compared to day 1 values ( $p<0.001$, for both comparisons; Table $4 a$ ).

When the degree of disability was compared across days 1,30 , and 90 , the number of subjects with grade IV (severe disability) decreased from 16 (53.3) to 4 (13.3) to $1(3.3 \%)$ subject, whereas those belonging to grade I MIDAS (little or no disability) increased from 6 (20) to 11 (36.6) to 20 (66.6\%), respectively. The CT group showed no change across three assessment points.

Perceived Stress Scale 10: There was a significant difference in both within-subjects factor (Time, $p<0.001$ ) and between-subjects factor (Groups, $p<0.001$ ). Also, the interaction between Time and Groups was significant $(p<$ 0.001 ). The post-hoc analysis showed a significant reduction in PSS scores for the AY group on days 30 and $90 \mathrm{com}$ pared to the day 1 values ( $p<0.01, p<0.001$, respectively).

The scores of perceived stress in the AY group changed significantly across the three assessments (days 1, 30, and 90). The number of subjects with low stress increased from 3 (10) to 7 (23.3) to $18(60 \%)$, while the number with moderate stress decreased from 25 (83.3) to 22 (73.3) to $11(36.6 \%)$, and with high perceived stress decreased from 2 (6.6) to 1 (3.3) to 0 subjects (Table $4 a$ ).

Heart Rate Variability: There was a significant interaction between time and groups for LF, HF power values in normalized units as well as LF/HF ratio $(p<0.05)$. The posthoc analysis showed a significant reduction in LF power and $\mathrm{LF} / \mathrm{HF}$ ratio, while HF power increased in the AY group on day 90 compared to their day 1 and day 30 values $(p<0.01$, $p<0.05$ respectively). There were no changes observed in the time domain measures of HRV (Table 4b).

Heart Rate: There was a significant difference in withinsubjects factor (Time, $p<0.05$ ). The post-hoc analysis with Bonferroni correction showed no significant difference across multiple comparisons for both groups (Table 4c).

Respiratory Rate: There was no significant difference in both within-subjects factor and between-subjects fac- 
Table 3. Details of the yoga program specially designed for the migraine patients are listed below. The description includes the category of practices, duration of each practice (s-seconds, min-minutes), number of repetitions, and the sequence of practices

\begin{tabular}{|c|c|c|c|}
\hline Sl. No. & Practices & Number of rounds & Duration \\
\hline 1. & $\begin{array}{l}\text { Loosening practices (Shithilikarana vyayama) } \\
\text { Neck up and down movement } \\
\text { Neck side to side movement } \\
\text { Shoulder rotation - clockwise and anti-clockwise } \\
\text { Shoulder cuff rotation - clockwise and anti-clockwise } \\
\text { Head rolling - clockwise and anti-clockwise, up and down movement }\end{array}$ & 5 rounds & $5 \mathrm{~min}$ \\
\hline 2. & Instant relaxation technique & 1 round & $1 \mathrm{~min}$ \\
\hline 3. & $\begin{array}{l}\text { Breathing practices } \\
\text { Ankle stretch breathing } \\
\text { Shashankasana breathing } \\
\text { Tiger stretch breathing } \\
\text { Uttanapadasana breathing - Single leg }\end{array}$ & 5 rounds each & $5 \mathrm{~min}$ \\
\hline $5 a$ & $\begin{array}{l}\text { Standing: } \\
\text { Padahasthasana } \\
\text { Ardha Chakrasana } \\
\text { Ardhakati Chakrasana } \\
\text { Trikonasana } \\
\text { Relaxation in standing posture }\end{array}$ & $\begin{array}{l}30 \mathrm{~s} \text { each } \\
\text { approximately }\end{array}$ & $30 \mathrm{~s}$ \\
\hline $5 b$ & $\begin{array}{l}\text { Sitting: } \\
\text { Janushirasana } \\
\text { Vajrasana } \\
\text { Ushtrasana } \\
\text { Shashankasana } \\
\text { Suptavajrasana } \\
\text { Vakrasana } \\
\text { Relaxation in sitting posture }\end{array}$ & $\begin{array}{l}30 \mathrm{~s} \text { each } \\
\text { approximately }\end{array}$ & $4 \mathrm{~min}$ \\
\hline $5 \mathrm{~d}$ & $\begin{array}{l}\text { Prone: } \\
\text { Bhujangasana } \\
\text { Shalabhasana } \\
\text { Dhanurasana }\end{array}$ & $30 \mathrm{~s}$ each & $1.5 \mathrm{~min}$ \\
\hline 6. & Deep relaxation technique & & $7 \mathrm{~min}$ \\
\hline 7. & Kriyas Kapalabhati & & $1 \mathrm{~min}$ \\
\hline \multirow[t]{2}{*}{8.} & Regulated breathing practices (Pranayama) & 1 min each & $3 \mathrm{~min}$ \\
\hline & $\begin{array}{l}\text { Nadishodhana Pranayama } \\
\text { Bhramari Pranayama } \\
\text { Ujjayi Pranayama }\end{array}$ & 1 min each & $3 \min$ \\
\hline 9. & Nadanusandhana (chanting) & & $3 \mathrm{~min}$ \\
\hline
\end{tabular}


Table 4. Demographic and clinical characteristics of subjects belonging to the AY and CT groups

\begin{tabular}{lrr}
\hline & AY & CT \\
\hline Age, years, mean \pm SD & $33.83 \pm 6.84$ & $31.46 \pm 7.81$ \\
Gender & 8 & 8 \\
$\quad$ Male & 22 & 22 \\
$\quad$ Female & & 12 \\
Clinical characteristics & 9 & 18 \\
$\quad$ Severity of headache (intensity of pain) & 21 & 29.8 \\
$\quad$ Moderate & 27.8 & 30 \\
$\quad$ Severe & 30 & 30 \\
$\quad$ Associated with nausea and/or vomiting (number of subjects) & 30 \\
$\quad$ Number of subjects using analgesics & \\
\hline
\end{tabular}

a. MIDAS score and PSS recorded on days 1, 30, and 90 in both AY and CT groups. Values are group mean \pm SD

\begin{tabular}{|c|c|c|c|c|c|c|}
\hline & \multicolumn{3}{|l|}{ AY } & \multicolumn{3}{|l|}{$\mathrm{CT}$} \\
\hline PSS & $21.20 \pm 4.83$ & $17.03 \pm 5.72 * *$ & $11.96 \pm 4.85^{* * * \text {, †十† }}$ & $22.30 \pm 3.36$ & $21.34 \pm 2.48$ & $21.51 \pm 3.34$ \\
\hline
\end{tabular}

${ }^{* *} p<0.01,{ }^{* * *} p<0.001,{ }^{\dagger} p<0.05,{ }^{\dagger \dagger} p<<0.001$, repeated measures ANOVA with post-hoc analysis.

* Comparing the day 1 values with respective days 30 and 90 values, ${ }^{\dagger}$ comparing days 30 and 90 values.

MIDAS, migraine disability assessment; PSS, perceived stress score.

b. Frequency domain and time domain measures of heart rate variability recorded on days 1, 30, and 90 in both AY and CT groups. The values are group mean $\pm \mathrm{SD}$

\begin{tabular}{|c|c|c|c|c|c|c|}
\hline & \multicolumn{3}{|l|}{ AY } & \multicolumn{3}{|l|}{ CT } \\
\hline & day 1 & day 30 & day 90 & day 1 & day 30 & day 90 \\
\hline LF, nu & $54.86 \pm 18.45$ & $50.72 \pm 17.25$ & $41.26 \pm 15.48^{* *, \dagger}$ & $43.51 \pm 18.33$ & $45.77 \pm 16.40$ & $46.04 \pm 16.85$ \\
\hline $\mathrm{HF}, \mathrm{nu}$ & $45.29 \pm 18.22$ & $48.90 \pm 18.15$ & $58.91 \pm 15.43^{* *, \dagger}$ & $56.71 \pm 18.30$ & $54.36 \pm 16.37$ & $54.14 \pm 16.87$ \\
\hline $\mathrm{LF} / \mathrm{HF}$, ratio & $2.06 \pm 2.79$ & $1.29 \pm 0.86$ & $0.84 \pm 0.59^{\dagger}$ & $1.04 \pm 0.97$ & $1.10 \pm 0.98$ & $1.09 \pm 0.89$ \\
\hline SDNN, ms & $34.99 \pm 18.86$ & $33.43 \pm 13.65$ & $34.33 \pm 18.47$ & $34.41 \pm 13.23$ & $33.73 \pm 20.27$ & $34.37 \pm 20.20$ \\
\hline RMSSD, ms & $25.49 \pm 19.63$ & $23.71 \pm 14.38$ & $28.16 \pm 24.60$ & $30.50 \pm 20.70$ & $30.41 \pm 26.39$ & $33.10 \pm 27.05$ \\
\hline pNN50, ms & $8.43 \pm 14.32$ & $7.72 \pm 12.41$ & $6.35 \pm 10.62$ & $11.88 \pm 18.74$ & $9.82 \pm 14.78$ & $12.51 \pm 19.23$ \\
\hline
\end{tabular}

** $p<0.01,{ }^{\dagger} p<0.05$, repeated measures ANOVA with post-hoc analysis.

* Comparing day 1 with day 30 and day 90 values, ${ }^{\dagger}$ comparing day 30 with day 90 values.

c. The HR and RR recorded on days 1, 30 and 90 in both AY and CT groups. The values are group mean \pm SD

\begin{tabular}{|c|c|c|c|c|c|c|}
\hline & \multicolumn{3}{|l|}{ AY } & \multicolumn{3}{|l|}{$\mathrm{CT}$} \\
\hline & day 1 & day 30 & day 90 & day 1 & day 30 & day 90 \\
\hline HR (BPM) & $82.95 \pm 11.53$ & $84.72 \pm 12.63$ & $78.53 \pm 11.12$ & $86.58 \pm 9.74$ & $87.05 \pm 11.93$ & $84.09 \pm 14.24$ \\
\hline $\mathrm{RR}(\mathrm{BrPM})$ & $18.30 \pm 3.03$ & $17.03 \pm 2.55$ & $16 \pm 2.59^{* *}$ & $17.76 \pm 3.72$ & $18.03 \pm 3.38$ & $18.41 \pm 3.87$ \\
\hline
\end{tabular}

** $p<0.01$, Repeated measures ANOVA with post-hoc analysis comparing the day 1 values with days 30 and 90 values. BPM, beats per minute; BrPM, breaths per minute; HR, heart rate; RR, respiratory rate. 
Table 4. (continued)

d. The integral EMG and RMS EMG recorded on days 1, 30, and 90 in both AY and CT groups. The values are group mean \pm SD

\begin{tabular}{|c|c|c|c|c|c|c|}
\hline & \multicolumn{3}{|l|}{ AY } & \multicolumn{3}{|l|}{$\mathrm{CT}$} \\
\hline & day 1 & day 30 & day 90 & day 1 & day 30 & day 90 \\
\hline Integral EMG, $\mu \mathrm{V}$ & $11.80 \pm 8.49$ & $8.74 \pm 4.85$ & $6.52 \pm 2.77^{* *, \dagger \dagger}$ & $9.31 \pm 3.90$ & $10.96 \pm 5.42$ & $12.04 \pm 6.31$ \\
\hline RMS EMG, $\mu \mathrm{V}$ & $133.43 \pm 58.25$ & $113.99 \pm 68.61$ & $75.44 \pm 35.19^{* * *, \dagger}$ & $128.50 \pm 69.53$ & $159.41 \pm 129.39$ & $128.31 \pm 65.87$ \\
\hline
\end{tabular}

** $p<0.01,{ }^{* * *} p<0.001,{ }^{\dagger} p<0.05,{ }^{\dagger \dagger} p<0.01$, repeated measures ANOVA with post-hoc analysis. ${ }^{*}$ Comparing day 1 with day 30 and day 90 values, ${ }^{\dagger}$ comparing day 30 with day 90 values.

tor. The interaction between time and groups was significantly different $(p<0.05)$.

The post-hoc analysis with Bonferroni correction suggested that there was a significant reduction in respiratory rate in the AY group on day 90 compared to day 1 values $(p<0.01$; Table $4 c)$.

Surface Electromyography: The mean RMS EMG showed a significant difference in within-subjects factor (time, $p<0.05$ ), between subjects factor (groups, $p<0.05$ ) and the interaction between time and groups $(p<0.01)$. The post-hoc analysis showed a significant reduction on day 90 compared to day 1 and day 30 values $(p<0.001$ and $p<0.05$, respectively).

Integral EMG $(p<0.001)$ showed a significant difference in the interaction between time and groups $(p<$ 0.001 ). The post-hoc analysis showed a significant reduction in integral EMG values in the AY group on day 90 compared to day 1 values $(p<0.01)$.

The control group showed no significant changes across assessments (days 30 and 90 , compared to day 1 ) for different variables $(p<0.05$; Table $4 \mathrm{~d})$.

Medication (NSAID) Use: The analgesic requirement on need basis, which was noticed in all 30 participants of the AY group (100\%) on day 1 reduced to 14 participants $(46.6 \%)$ by day 30 and was noticed in 6 participants $(20 \%)$ on day 90 compared to the CT group where the requirement reduced from 30 participants (100\%) on day 1 to 27 participants (90\%) on day 30 , and to 26 participants $(86.66 \%)$ on day 90 .

\section{Discussion}

A combined Ayurveda and Yoga therapy intervention for 90 days reduced migraine-related disability, levels of perceived stress, and sympathetic arousal. The foremost treatise of Ayurveda, Charaka Samhita considers Yoga as an integral part of Ayurveda where the balance of Doshas (body humor) is achieved through Ayurveda and psycho- logical well-being through Yoga therapy. Hence, we made an attempt to study the combined effect of Yoga and Ayurveda in individuals with migraine headache.

Migraine is a leading cause, among both men and women, for years spent with disability at physical, mental, and social levels [4]. The MIDAS scores which were high in the present study decreased significantly in the AY group. This can primarily be attributed to the reduced severity of pain, frequency of headache, and improved quality of life. Similar changes in MIDAS were reported earlier, where Ayurveda medicines were given along with regulated diet and lifestyle. Improved digestive fire (agni) and better acid-alkaline balance in the digestive system were the proposed mechanisms [12]. A mindfulness-based stress reduction program along with conventional prophylaxis also showed a significant reduction in migraine-related disability. It was speculated that improved emotional regulation, less pain catastrophizing, and increased pain acceptance are the reasons behind the positive results observed [23].

Stress is considered as an important factor for trigger and perpetuation of migraine headache [5]. The higher perceived stress scores observed in AY and CT groups indicate the impact of stress on the present study population. The severity of perceived stress decreased significantly in the AY group, with more than $60 \%$ of the participants moving to low perceived stress levels. Similarly, significant improvement in perceived stress, marked relief in pain, and reduction in salivary cortisol levels were observed in 24 women with headache or back pain following the practice of Iyengar Yoga, twice a week for 90 min duration [24]. A previous report implied that a single session of Abhyanga reduced subjective stress experience, lowered heart rate, and systolic blood pressure [25]. Abhyanga which was part of Ayurveda intervention for 6-8 days in the present study, was expected to relax and rejuvenate an individual physically and mentally.

The evoked autonomic changes were recorded during the 3-min frowning period. Reduction in the duration of 
recording from standard 5 to $3 \mathrm{~min}$ was based on the subjective experience based on our pilot study where subjects expressed discomfort and were anxious about the onset of a migraine attack following frowning for $5 \mathrm{~min}$. One such study validates the short-term HRV [26].

An increased HF and decreased LF component of HRV along with reduced heart rate and respiratory rate in the present study gives a clear indication of sympathovagal balance shifting towards vagal dominance in the AY group. A previous study on healthy undergraduate medical students showed a significant reduction in stress, decrease in LF component, and increase in HF component of HRV spectrum following 2 months of pranayama practice [27]. The changes were attributed to the inhibitory signals generated during the process of pranayama from cardiorespiratory system leading to modulation of autonomic system resulting in parasympathetic dominance. Heightened baroreflex sensitivity and improved oxygenation have been the proposed underlying mechanisms for the decreased heart rate, systolic blood pressure, and improved oxygen consumption observed in the study [28]. Brown and Gerbarg in a review reported that yoga-breathing interventions increase HRV, improve sympathovagal balance, and promote stress resilience. Coherent breathing and resonant breathing, using a fixed rate of 3 and a half to 6 breaths per minute (bpm), have been shown to increase HRV and parasympathetic nervous system activity [29].

Increased parasympathetic activity may cause reduced firing of the paragigantocellular nucleus of the medulla to locus coeruleus, and decreased stimulation of locus ceruleus could reduce norepinephrine output, resulting in relaxation, quiescence, and reduced respiratory and heart rates [30]. Using real-time functional MRI, attempts were made in healthy volunteers to modulate the activation of their own anterior cingulate cortex to alter their pain experience [31]. The association between increased cortical thickness in pain-related brain regions (including anterior cingulate cortex, bilateral parahippocampal gyrus) and lowered pain sensitivity in Zen meditators compared to non-meditators has added a probable supporting evidence for the underlying mechanisms [32]. Some meditation types such as mindfulness are associated with enhancements in cognitive control, emotional regulation, positive mood, and acceptance. Each of them play a role in pain modulation [33].

Streeter et al. [34], in a comprehensive review, have reported that asanas, pranayama, and meditation including chanting can shift sympathovagal balance to vagal dominance, enhance activity of the gamma-aminobutyric acid system, and reduce allostatic load. The authors have also hypothesized that the regulation of hypothala- mo-pituitary-adrenal axis through the practice of yoga is one of the underlying mechanism.

Furthermore, stress is also known to increase muscle activation. In chronic pain, sympathetic activity due to nociceptive stimulation may cause disturbances of blood flow regulation in the affected muscle and enhance muscle activation [35]. A previous report on yoga in tensiontype headache has shown to reduce EMG amplitude at rest and during mental activity [36]. Reduced sympathetic activity following the practice of yoga is also known to bring down muscle activity.

Hence, the present study demonstrated that the autonomic arousal and sEMG activity during frowning were substantially lower on day 90 , inferring a positive role of Ayurveda and yoga in an attenuated stress response.

Two polyherbal combinations were used in the Ayurveda treatment protocol (Kallyanaka Ghrita for internal oleation and Pathyakshadhatryadi kashaya as oral medicine post virechana). Kallyanaka ghrita is one of the combinations mentioned in Bower manuscript and traditional Ayurveda texts and also assessed scientifically through HPTLC [37].

The orally administered decoction (Pathyakshadhatyradi Kashaya) used in this study for 75 days has 7 herbs. Triphala (3 herbs) has adaptogenic effects [38], Azadirachta Indica has anti-inflammatory, anti-proliferative properties, turmeric with the active ingredient curcumin has anti-inflammatory effect [39], Tinospora cardifolia has anti-oxidant, immunomodulatory properties [40], and Andrographis paniculata has shown hepatoprotective, antioxidant, and anti-inflammatory properties [41].

Hence, the present study illustrates that a combined intervention of traditional Ayurveda and yoga therapies can reduce migraine-related disability and perceived stress by establishing autonomic balance and reduced frontalis muscle activity over the forehead.

\section{Limitations and Future Directions}

Self-selection of intervention by the subjects was the major limitation of the study. Bigger sample size with a randomized controlled trial with a longer follow-up would offer more generalized results.

\section{Conclusion}

Ayurveda and yoga therapy reduce migraine-related disability by reducing perceived stress, improving autonomic balance, and reducing muscle tension. 


\section{Acknowledgments}

We acknowledge the contribution of Dr. Raghavendra Bhat for technical support and Dr. Prajna Shetty for assisting in data collection and yoga training.

\section{Disclosure Statement}

This work received no specific grant from any funding agency, commercial, or not-for-profit sectors.

\section{Author Contribution}

Dr. Vasudha M. Sharma was involved in conceptualizing the study, reviewing the literature, planning Ayurveda intervention, recruitment of subjects and assessments, data analysis, and preparing the manuscript. Dr. Manjunath N.K. was involved in conceptualizing and designing the study, planning statistical analysis, and preparing the manuscript. Dr. Nagendra H.R. was instrumental in providing guidance for the whole study, designing the yoga therapy module, and preparing the manuscript.

\section{References}

1 Dodick DW: Review of comorbidities and risk factors for the development of migraine complications (infarct and chronic migraine). Cephalalgia 2009;29(suppl 3):7-14.

2 Dawn CB, Marcia FT, Rupnow T, Richard BL: Assessing and managing all aspects of migraine: migraine attacks, migraine-related functional impairment, common comorbidities, and quality of life. Mayo Clin Proc 2009; 84:422-435.

3 Stewart WF, Lipton RB, Whyte J, Dowson A, Kolodner K, Liberman JN, Sawyer J: An International study to assess reliability of the migraine disability assessment (MIDAS) score. Neurology 1999;53:988-994.

4 Maki K, Vahtera J, Virtanen M, Elovainio M, Keltikangas-Jarvinen L, Kivimaki M: Work stress and new-onset migraine in a female employee population. Cephalalgia 2008;28:18-25.

5 Moon H, Seo JG, Park SP: Perceived stress in patients with migraine: a case-control study. J Headache Pain 2017;18:73.

6 Cortelli P, Pierangeli G, Parchi P, Contin M, Baruzzi A, Lugaresi E: Autonomic nervous system function in migraine without aura Headache 1991;31:457-462.

7 Jensen R, Fuglsang-Frederiksen A, Olesen J: Quantitative surface EMG of pericranial muscles in headache, a population study. Electroencephalogr Clin Neurophysiol 1994;93:335344.

8 Leistad RB, Sand T, Westgaard RH, Nilsen KB, Stovner LJ: Stress-induced pain and muscle activity in patients with migraine and tensiontype headache. Cephalalgia 2006;26:64-73.

9 Goadsby PJ: Bench to bedside advances in the 21 st century for primary headache disorders: migraine treatments for migraine patients. Brain 2016;139:2571-2577.

10 Jaideep SS, Nagaraja D, Pal PK, Sudhakara D, Satyaprabha TN: Modulation of cardiac autonomic dysfunction in ischemic stroke following Ayurveda (Indian System of Medicine) Treatment. Evid Based Complement Alternat Med 2014;2014:634695.

11 Peterson CT, Lucas J, John-William L, Thompson JW, Moseley MA, Patel S, Peterson SN, Porter V, Schadt EE, Mills PJ, Tanzi RE, Doraiswamy PM, Chopra D: Identification of al- tered metabolomic profiles following a panchakarma-based Ayurvedic Intervention in healthy subjects: The Self-Directed Biological Transformation Initiative (SBTI). Sci Rep 2016;6:32609.

12 Vaidya PB, Vaidya BS, Vaidya SK: Response to Ayurvedic therapy in the treatment of migraine without aura. Int J Ayurveda Res 2010;1:30-36.

13 Mishra K, Singh P, Bunch SJ, Bunch SJ, Zhang $\mathrm{R}$ : The therapeutic value of yoga in neurological disorders. Ann Indian Acad Neurol 2012. 15:247-254.

14 Sargent J, Solbach P, Coyne L, Spohn H, Segerson J: Results of a controlled, experimental, outcome study of nondrug treatments for the control of migraine headaches. J Behav Med 1986;9:291-323.

15 International Headache Society: International classification of headache disorders. Cephalalgia 2013;33:629-808.

16 Cohen S, Williamson GM: Perceived stress in a probability sample of the United States. Soc Psychol Health 1988:31-67.

17 Gada MT: A comparative study of efficacy of EMG bio-feedback and progressive muscular relaxation in tension headache. Indian J Psychiatry 1984;26:121-127.

18 De Luca CJ: The use of surface electromyography in biomechanics. J Appl Biomech 1997; 13:135-163.

19 Yadunandan U (ed): Ashtanga Hrudayam of Vagbhata with Vidyotini Hindi commentary, ed 12. Varanasi, Chaukhambha Sanskrit Sansthan, 1997, pp 380-474.

20 Rais A, Bhatted S: Clinical study to evaluate the effect of Virechana karma on serum electrolytes. Ayu 2013;34:379-382.

21 Shastri P (ed): Sharangadhara Samhita, Madhyama Khanda. Varanasi, Oriental Publishers and Distributors, 1985, vol. 2, pp 145-147.

22 Niteshwar K, Vidayanath R: Sahasra Yoga Churnaprakarana 62. Varanasi, Chaukhambha Bharati Academy, 2007.

23 Wells RE, Burch R, Paulsen RH, Wayne PM, Houle TT, Loder E: Meditation for migraines: a pilot randomized controlled trial. Headache 2014;54:1484-1495.

24 Michalsen A, Grossman P, Acil A, Langhorst J, Ludtke R, Esch T, Stefano GB, Dobos GJ:
Rapid stress reduction and anxiolysis among distressed women as a consequence of a threemonth intensive yoga program. Med Sci Monit 2005; 11:555-561.

25 Basler AJ: Pilot study investigating the effects of Ayurvedic Abhyanga massage on subjective stress experience. J Altern Complement Med 2011;17:435-440.

26 Salahuddin L, Cho J, Jeong MG, Kim D: Ultrashort term analysis of heart rate variability for monitoring mental stress in mobile settings. Conf Proc IEEE Eng Med Biol Soc 2007; 4656-4659.

27 Bhimani NT, Kulkarni NB, Kowale A, Salvi S Effect of pranayama on stress and cardiovascular autonomic function. Indian J Physiol Pharmacol 2011;55:370-377.

28 Mason H, Vandoni M, deBarbieri G, Codrons E, Ugargol V, Bernardi L: Cardiovascular and respiratory effect of Yogic slow breathing in the Yoga beginner: what is the best approach? Evid Based Complement Alternat Med 2013; 2013:743504

29 Brown RP, Gerbarg PL: Yoga breathing, meditation, and longevity. Ann N Y Acad Sci 2009;1172:54-62.

30 Thirthalli J, Naveen GH, Rao MG, Varambally S, Christopher R, Gangadhar BN: Cortisol and antidepressant effects of yoga. Indian $\mathrm{J}$ Psychiatry 2013;55:405-408.

31 deCharms RC, Maeda F, Glover GH, Ludlow D, John MP, Soneji D, John DE, Gabrieli JD, Mackey SC: Control over brain activation and pain learned by using real-time functional MRI. Proc Natl Acad Sci USA 2005;102:18626-18631.

32 Grant JA, Courtemanche J, Duerden EG Duncan GH, Rainville P: Cortical thickness and pain sensitivity in Zen meditators. Emotion 2010;10:43-53.

33 Grossman P, Niemann L, Schmidt S, Walach $\mathrm{H}$ : Mindfulness-based stress reduction and health benefits. A meta-analysis. J Psychosomat Res 2004;57:35-43.

34 Streeter CC, Gerbarg PL, Saper RB, Ciraulo DA, Brown RP: Effects of yoga on the autonomic nervous system, gamma-aminobutyric-acid, and allostasis in epilepsy, depression, and post-traumatic stress disorder. Med Hypotheses 2012;78:571-579. 
35 Larsson SE, Larsson R, Zhang Q, Cai H, Oberg PA: Effects of psychophysiological stress on trapezius muscles blood flow and electromyography during static load. Eur J Appl Physiol 1995;71:493-498.

36 Bhatia R, Dureja GP, Tripathi M, Bhattacharjee M, Bijlani RL, Mathur R: Role of temporalis muscle over activity in chronic tension type headache: effect of yoga based management. Indian J Physiol Pharmacol 2007;51:333-344.
37 Natsume Y, Neeraj K, Tripathi SM, Nose M, Bhutani KK: Kalyanaka ghrita: an example of intertextuality among the Bower manuscript, Charak samhita, Susruta samhita, Astangahrdayam samhita and Ayurvedic Formulary of India (AFI). Ind J Trad Knowl 2015;14:519-524.

38 Peterson CT, Denniston K, Chopra D: Therapeutic uses of Triphala in Ayurvedic Medicine. J Altern Complement Med 2017;23:607614.

39 Gupta SC, Patchva S, Aggarwal B: Therapeutic roles of curcumin: lessons learned from clinical trials. AAPS J 2013;15:195-218.
40 Subramanian M, Chintalwar GJ, Chattopadhyay S: Antioxidant properties of a Tinospora cordifolia polysaccharide against ironmediated lipid damage and gamma-ray induced protein damage. Redox Rep 2002;7: 137-143.

41 Chua LS: Review on liver inflammation and anti inflammatory activity of Andrographis paniculata for hepatoprotection. Phytother Res 2014;28:1589-1598. 